\title{
st \\ Indistinguibilidade, não reflexividade, ontologia e física quântica
}

\author{
Jonas Rafael Begker Arenhart \\ \& Décio Krause
}

\begin{abstract}
$\ddot{\leftrightarrow}$
RESUMO

Tem sido reconhecido como razoável assumir que, uma vez que pensemos nos objetos que estariam por trás do desenvolvimento formal das teorias físicas, a física quântica nos comprometeria com entidades que podem ser assumidas como absolutamente indistinguíveis e, de certa forma, como sendo desprovidos de individualidade. Neste artigo, discutiremos primeiramente, de modo breve e geral, a natureza desse compromisso, como ele pode ser compreendido em termos metafísicos, bem como sua relação com os sistemas de lógica utilizados para falar sobre os objetos com os quais supostamente nos comprometemos. Apresentamos então alguns dos principais aspectos da mecânica quântica ortodoxa, aos quais usualmente se recorre quando se deseja fornecer argumentos que possam sustentar uma ontologia de objetos com essas características, ou seja, de objetos indistinguíveis e sem individualidade. Por fim, exibimos um sistema de teoria de conjuntos, a teoria de quase conjuntos, que busca captar formalmente e de modo natural essas características e, assim, pode ser utilizada como lógica subjacente para fundamentar uma metafísica de não indivíduos.
\end{abstract}

PaLAVRAS-GhaVE • Mecânica quântica. Ontologia. Não individualidade. Indistinguibilidade. Quase conjuntos.

\section{INTRODUÇÃO}

É bem sabido que a física quântica é uma fonte constante de perplexidades filosóficas. O famoso gato de Schrödinger, a existência de estados de superposição, o colapso da função de onda, a dualidade onda-partícula, a complementaridade, a não localidade são alguns exemplos de conceitos e situações, via de regra, sem paralelo na física clássica (não detalharemos qualquer dessas situações aqui; ao leitor interessado, recomendamos os textos de Pessoa Junior, 2003, 2006). Ademais, deve-se esclarecer que, por física quântica, entenderemos aqui a mecânica quântica não relativista (por vezes dita mecânica quântica ortodoxa), cuja formulação mais difundida (pelo menos no con- 
texto filosófico) utiliza a teoria dos espaços de Hilbert e, somente quando mencionado explicitamente, faremos referência a sua versão relativista ou a outra versão da teoria. ${ }^{1}$

Uma dentre essas questões intrigantes, de especial interesse tanto para os metafísicos quanto para os lógicos, diz respeito à identidade e à indistinguibilidade das entidades básicas com as quais trata a teoria. ${ }^{2}$ Em geral, os diversos autores referem-se a essas entidades como partículas elementares, mas o uso que faremos desse termo pode congregar campos ou outras entidades, como ficará claro abaixo. Segundo uma posição que floresceu junto com o próprio desenvolvimento da teoria em seus primórdios, posteriormente batizada de concepção recebida acerca da individualidade das partículas elementares, essas entidades, além de poderem ser "absolutamente" indistinguíveis, seriam objetos que de certa forma não possuiriam individualidade. ${ }^{3}$ Essa ausência de individualidade, ou simplesmente não individualidade, pode, por sua vez, ser fundamentada no que se reconheceu como a impossibilidade das partículas em serem identificáveis depois de "misturadas" (superpostas) e, por vezes, na total ausência de sentido em afirmar que duas ou mais partículas de determinado tipo são iguais ou diferentes como, por exemplo, apregoou Schrödinger (cf. French \& Krause, 2006). Assim, físicos notáveis como Roger Penrose, dentre vários outros que poderiam ser citados, afirmam que "partículas diferentes [querendo aqui dizer que não se trata da mesma partícula] de um mesmo tipo não podem ter identidades separadas umas das outras" (Penrose, 1989, p. 294), ou que “dois elétrons, por exemplo, são exatamente o mesmo um com o outro" (p. 297). Claro que isso é um abuso de linguagem. Na verdade, o que ele quer dizer não é que elétrons, por exemplo, sejam todos numericamente o mesmo objeto, no sentido de haver somente um deles (de acordo com o significado usual de "identidade" em matemática e em filosofia, segundo o qual, entidades idênticas são a mesma entidade), mas que são qualitativamente indiscerníveis. Essa suposição, aparentemente corroborada pela física quântica, como se verá, acarreta situações filosoficamente complicadas, por exemplo, a lógica subjacente às formulações usuais de tal teo-

1 A teoria quântica (relativista e não relativista) admite abordagens diversas; citamos as integrais de caminho de Feynmann, a abordagem algébrica, a "convexa", a operacional e a que utiliza reticulados, dentre várias outras formulações possíveis. Styer e colaboradores (2002) mencionam nove formulações da mecânica quântica. $\mathrm{O}$ uso de lógicas não clássicas nesse contexto originou-se da proposta de Birkhoff e Von Neumann em 1936, e foi levada adiante, ao menos parcialmente, por Reichenbach e por Paulette Février. O livro de Jammer (1974) apresenta uma boa discussão do assunto.

2 Assumimos aqui uma postura compatível com a de Sunny Auyang, para quem "teorias físicas são sobre coisas" (Auyang, 1995, p. 152) e que, apesar de que nas teorias quânticas de campos (mecânica quântica relativista) os campos constituam a entidade ontológica básica, "esta é uma coisa, e não uma região espacial” (p.15o). Essa discussão merece aprofundamento, sem duvida, mas não aqui.

3 Chamamos aqui as partículas quânticas de objetos para evitar a monotonia terminológica e por falta de palavra melhor; todavia, o uso que aqui fazemos deve ser o mais neutro possível, sem comprometer-nos com a carga conceitual associada ao termo. 
ria (ou teorias) é a lógica clássica (e a matemática padrão), a qual acarreta que, uma vez que tenhamos duas entidades (ou dois objetos quaisquer), eles são necessariamente distintos. O problema é que nem sempre essa distinção pode ser apontada, como acontece em certos casos mesmo dentro da matemática usual. ${ }^{4}$ Se aceitarmos que tal é o caso no tocante às entidades quânticas, estaremos assumindo que a indiscernibilidade se deve unicamente a nossa incapacidade de distingui-las, no sentido de que há uma ignorância epistemológica. Aparentemente, esse não é o caso, pois não se trata de que haja alguma forma de "variável oculta", ou seja, algum tipo de propriedade ou relação que, apesar de desconhecida, poderia conferir uma diferença entre os objetos; ao contrário, pelo que tudo indica, estamos perante uma questão ontológica, ou seja, lidando com entidades que não se comportam como se fossem "objetos clássicos”, ou indivíduos, como preferimos dizer, ou seja, objetos que se comportam como se fossem entidades que se conformam às leis, principalmente da identidade, da lógica clássica e da matemática padrão. 5

Como podemos entender esses conceitos, e como seus proponentes viam a ligação entre eles? De um ponto de vista metafísico, se aquilo que estamos entendendo por indistinguibilidade de dois objetos é uma relação entre esses objetos, que vigoraria caso eles possuíssem as mesmas propriedades, então a possibilidade de haver dois objetos indistinguíveis estaria ligada à antiga discussão sobre a validade do princípio de identidade dos indiscerníveis (PII). Segundo este princípio, objetos que partilham todas as propriedades, ou seja, que são indistinguíveis, são o mesmo objeto (são idênticos). Evidentemente, caso o princípio seja válido, indistinguibilidade e identidade colapsam na mesma relação, já que a recíproca é, aparentemente, uma incontestável lei lógica. Dentre os exemplos famosos empregados para tentar refutar PII está o de um universo contendo apenas duas esferas metálicas perfeitamente semelhantes, cada uma a uma milha de distância da outra, tal como proposto por Max Black (1952). Neste caso, alega-se, temos a diversidade numérica das duas esferas, mas nenhuma propriedade que se possa utilizar para distinguir entre elas e, assim, PII não seria um princípio necessariamente válido. Não entraremos agora na discussão sobre os méritos desse exemplo, bastante discutido na literatura.

4. Um caso paradigmático é o seguinte. Na teoria de conjuntos ZFG (Zermelo-Fraenkel com o axioma da escolha), pode-se provar que há uma boa ordem sobre todo conjunto. Uma boa ordem sobre um conjunto Xé uma ordem total sobre $\mathrm{X}$ relativamente à qual todo subconjunto não vazio de $\mathrm{X}$ possui menor elemento. Logo, há uma boa ordem sobre o conjunto $\mathrm{R}$ dos números reais. O problema é que não se pode representar essa boa ordem (nem qualquer outra) por uma fórmula da linguagem de ZFC. Consequentemente, dados dois subconjuntos disjuntos de R (na ordem usual), digamos (o,1) e (2,3), eles têm menores elementos que são distintos. Porém, essa distinção não pode ser expressa na linguagem de ZFC.

5 J.-M. Lévy-Leblond e F. Balibar (1990) chegam a propor que essas entidades mereceriam até mesmo um outro nome, devido a sua natureza discrepante; chamando-as de quantons. 
O que a mecânica quântica trouxe de novo para esse debate? Sabemos que, na mecânica clássica, podemos também ter partículas indistinguíveis no sentido discutido acima e, no entanto, não se costuma defender que essa indistinguibilidade possa afetar o status de indivíduo de cada uma dessas partículas. Com efeito, mesmo partilhando todas as propriedades físicas, duas de tais partículas sempre se diferenciam por sua posição espaço-temporal: elas são impenetráveis. O ponto crucial no contexto quântico é saber se existem situações em que a própria noção de identidade utilizada para formular o PII deixa de fazer sentido para as entidades tratadas pela teoria. Se sustentarmos essa posição, os enunciados sobre igualdade ou diferença de partículas, em muitas situações, não poderiam ser afirmados com sentido e a individualidade das partículas, de certo modo, perder-se-ia, e elas poderiam ser consideradas como não indivíduos (cf. French e Krause (2006, cap. 4), onde se apresentam concepções metafísicas distintas, porém compatíveis com a mecânica quântica ortodoxa). Nesses casos, nem sequer podemos utilizar as partículas como contraexemplo para o PII, pois ele não poderia nem mesmo ser adequadamente formulado, uma vez que requer a identidade em sua formulação. Em uma linguagem de segunda ordem, podemos escrever o PII assim: $\forall F(F(x) \leftrightarrow F(y)) \rightarrow x=y$, onde $x$ e $y$ são variáveis individuais e $F$ é uma variável para predicados de indivíduos.

Do ponto de vista metafísico, temos então a constatação aparentemente óbvia de que a situação relativamente à discussão formal de uma ontologia para a mecânica quântica torna-se bastante complexa, pois se depara com o que está implícito na lógica subjacente (recordemos que alguma forma do PII está presente na lógica tradicional como uma de suas leis básicas). Uma das razões para esta complexidade funda-se no fato aparente de que uma metafísica englobando não indivíduos pode parecer algo pouco usual, dada a aparente escassez de exemplos na história da filosofia. Informalmente, um indivíduo seria uma entidade que pode ser reidentificada como sendo aquela mesma entidade de uma situação anterior. No entanto, é interessante observar que certos itens não podem ser considerados indivíduos nesse sentido, como os universais ou os objetos denotados por termos de massa (como "água" ou "ouro"), que não podem ser reidentificados como sendo o mesmo em situações diversas. Uma amostra de água, digamos contendo um litro, depois de colocada em um tanque maior, não pode mais ser identificada; além disso, se dividirmos o conteúdo do tanque em duas partes, teremos água em cada uma delas, algo que aparentemente não ocorre com os indivíduos (aparentemente, eles não podem ser espalhados pelo espaço e permanecerem sendo eles mesmos). Da mesma forma, isso acontece com o dinheiro depositado em um banco. Alguns autores, tais como Paul Teller, chegam a fazer uma associação entre partículas indiscerníveis e moedas em um banco, no sentido de que não há como dizer quais são as nossas moedas... (cf. Teller, 1998, p. 115). Todavia, se consideramos que os não 
indivíduos são entendidos, no caso da mecânica quântica, como particulares (por oposição aos universais) para os quais a noção de igualdade não faz sentido, ${ }^{\mathbf{6}}$ eles podem em algum sentido ter as mesmas propriedades e serem sujeitos de predicação em enunciados da teoria. Para tanto, devemos reconhecer que ainda não se tentou fundamentar com muito rigor um sistema metafísico desenvolvido especialmente para tratar das peculiaridades deste tipo de objetos (cf. Krause, 2010). Em geral, quando estudamos a metafísica associada a uma teoria científica, ou seja, quando desejamos saber que tipo de objetos existe, uma vez que adotemos uma certa teoria ou, como se diz usualmente, o mobiliário do mundo segundo a teoria adotada, devemos ser capazes de desenvolver uma ontologia baseada naquilo que a teoria nos fornece. Contudo, no caso da mecânica quântica, em que segundo a concepção recebida (quântica) os objetos que constituem o mundo podem ser não indivíduos, ficamos ainda com muito a ser explicado, pois não temos uma "metafísica de não indivíduos" suficientemente desenvolvida. Dito sem muito rigor, por não indivíduos entendemos entidades (por falta de uma palavra mais adequada) que podem ser agregadas em coleções contendo mais de uma de tais entidades, mas tais que não há sentido em tentar ordenar uma tal coleção de modo que uma ordenação se distinga de outra qualquer. Para todos os efeitos, a ordem não importa, mas apenas a natureza dos elementos envolvidos e a quantidade de tais elementos. Exemplos típicos seriam as partículas elementares tais como descritas pela física quântica, como se verá mais abaixo. Um indivíduo, por outro lado, tem a peculiaridade de poder ser identificado como tal. Suponha-se, por exemplo, que estejamos observando formigas irem e virem de seu formigueiro. Acompanhamos uma delas, que se parece em muito com as demais. Ela entra no formigueiro e dele continuam a sair formigas. Podemos dizer se "nossa" formiga saiu de novo? Ora, podemos marcá-la, digamos com um pouco de tinta vermelha e, assim, segui-la e discerni-la das demais. No tocante às entidades quânticas, há muito tempo Schrödinger (1953, p. 56) apregoou que “não se pode marcar um elétron, não se pode pintá-lo de vermelho". Os objetos quânticos não são como as formigas. ${ }^{7}$

Como não se tem uma concepção metafísica bem desenvolvida sobre como devemos entender a não individualidade, temos também algumas dificuldades associadas no campo da lógica. Em geral, costuma-se esquecer que uma lógica engloba várias

6 Insistamos nesse ponto. Nossa relutância em aceitar que a noção de identidade (e a diferença) "faça sentido" neste caso reside no fato de que, aceitando-o, comprometemo-nos com alguma teoria da identidade (e da diferença). A teoria "clássica" da identidade traria problemas para o caso das partículas elementares, como esperamos o corpo do artigo deixe transparecer.

7 Poderíamos ser ainda mais incisivos e questionar a identificação até mesmo da formiga pintada. Com efeito, Hume argumentou (com razão, a nosso ver, cf. Krause, 2011) que a identidade de objetos (a sua reidentificação) é uma ficção da nossa imaginação, e que fazemos isso devido ao hábito. Para uma discussão inicial sobre a posição de Hume nesse quesito, bem como os possíveis vínculos com a física quântica, ver Krause \& Arenhart, 2006. 
teses relevantes para uma metafísica e para uma ontologia (cf. da Costa, 2002). No caso das partículas elementares, isso pode ser visto com bastante clareza. Inicialmente, vamos enfatizar que um dos possíveis modos de entender os não indivíduos consiste em considerá-los como entidades que não obedecem à teoria da identidade da lógica e da matemática tradicionais; em particular, a própria noção de identidade não se lhes aplicaria, de forma que tais entidades não poderiam entrar em relações de identidade ou de diferença. Se os objetos com os quais estamos tratando não podem entrar com sentido em relações de identidade ou diferença, não está claro se podemos utilizar a lógica clássica com identidade para tratar desses objetos, pois, nesse caso, em particular, todos os objetos sujeitos a essa lógica satisfariam certas leis da identidade, em particular, a propriedade reflexiva da identidade (também chamada muitas vezes de "lei da identidade"), segundo a qual, falando informalmente, todo objeto é idêntico a si mesmo. Mais ainda, segundo essa teoria, uma vez que se tenha duas de tais entidades, há uma diferença entre elas, ainda que essa diferença muitas vezes não possa ser explicitada, por exemplo, por uma fórmula da linguagem empregada (cf. nota 4). No entanto, é notório que os físicos consideram partículas elementares da mesma espécie, tais como, por exemplo, elétrons, como absolutamente indiscerníveis (recordem-se as frases de Penrose mencionadas acima).

Assim, associada a uma mudança em nossas concepções metafísicas, restringindo ou abandonando a concepção usual, segundo a qual a identidade e diferença fazem sentido para todos os objetos, que são sempre, pelo menos em princípio, identificáveis, temos uma motivação para buscar uma nova lógica, distinta da usual, em que tais objetos possam ser adequadamente representados. Se a identidade e diferença falham para esses objetos, então uma das condições para que os sistemas de lógica sejam candidatos razoáveis para fundamentar a concepção recebida é que violem, em particular, a propriedade reflexiva da identidade. Os sistemas de lógica que divergem da lógica clássica relativamente a sua teoria da identidade, em particular aqueles sistemas em que a propriedade reflexiva não se aplica irrestritamente, são conhecidos como lógicasnão reflexivas.

Nosso objetivo, neste artigo, é discutir alguns aspectos da mecânica quântica, com ênfase na teoria não relativista, levando em conta noções como as de indistinguibilidade, identidade e não individualidade. Relacionaremos estas noções com um sistema de lógica não reflexiva, e argumentaremos que esse sistema pode servir como um dos possíveis sistemas de lógica associados a uma metafísica que admita a existência de não indivíduos, resultando, em particular, que poderemos sustentar, contrariamente a Quine, que há entidades sem identidade. Com isso, buscaremos esclarecer essas noções e argumentaremos que a lógica aqui proposta capta de modo natural o uso que fazemos desses conceitos no contexto da física quântica. Começaremos discutindo o que vamos entender por ontologia e metafísica. 


\section{Ontologia E LÓGicA}

\subsection{Ontologia ou ontologias?}

Em geral, em discussões sobre metafísica, a palavra "ontologia" pode tomar diferentes sentidos. Em alguns casos, pode ser usada até mesmo como sinônima de metafísica, em outros, como um ramo desta, pois, como se argumenta algumas vezes, nem todos os problemas em metafísica são problemas em ontologia. Nessas circunstâncias, a ontologia é vista por alguns filósofos como o principal ou mais central ramo da metafísica (cf. Lowe, 1998). Neste segundo caso, costuma-se encontrar algum acordo sobre que tipo de problemas devem ser englobados sob o rótulo "ontologia”. No seu sentido tradicional, trata-se do estudo daquilo que há, das características mais gerais daquilo que existe, e sobre como podem ser classificados esses seres. Assim, se entendermos ontologia nesse sentido, deveremos estudar aquilo que usualmente se chama de "categorias ontológicas" (cf. van Inwagen, 2010), de modo que devemos buscar saber se existem universais, indivíduos, eventos e estados de coisas, dentre outros elementos.

Todavia, além desse sentido, que poderíamos classificar como o da ontologia tradicional, tambémé muito comum discutir ontologia relativamente a alguma teoria científica, como, por exemplo, a ontologia de uma das versões da mecânica quântica não relativista, ou a ontologia de uma teoria quântica de campos. Neste segundo sentido, poderíamos talvez falar de uma ontologia naturalizada. Este modo de conceber a ontologia está comumente associado ao nome de Quine (cf. 1964), que propunha um critério de compromisso ontológico, segundo o qual, falando por alto, aquilo com o que uma teoria, formulada em uma linguagem de primeira ordem sob certas condições, compromete-se ontologicamente são os objetos que devem existir para que sejam verdadeiras as sentenças existencialmente quantificadas da teoria. Assim, para considerar um exemplo trivial, uma teoria que tenha entre suas sentenças verdadeiras “ $\exists$ ( $\mathrm{x}$ ) (x é um cachorro)" teria que contar com cachorros em sua ontologia e, desse modo, estaria comprometida com esse tipo de objeto.

Como podemos entender a relação entre esses dois usos do termo "ontologia"? Será que são compatíveis? Se a ontologia deve descrever (ou descobrir) a estrutura mais geral daquilo que há, como poderia ser relativa a uma teoria, dado que diferentes teorias fornecem informações muito diferentes sobre o que há no mundo? É interessante observar que os dois tipos de investigação não são excludentes. Se assumirmos que a ontologia em seu sentido naturalizado não implica a tese mais forte de que apenas o que existe é aquilo com que se comprometem nossas teorias científicas, então podemos sustentar uma posição que busque compatibilizar os dois sentidos da palavra. A ontologia, no sentido tradicional, fornece um estudo a priori daquilo que pode exis- 
tir, enquanto a ontologia no sentido naturalizado busca estabelecer a relação dessas categorias com o mundo empírico (ou fenomênico), com aquilo que nossas teorias científicas dizem que existe de fato (módulo de uma teoria) e, portanto, de certa forma depende de alguns aspectos da investigação empírica (cf. Lowe, 1998). Nesse sentido, encontramos diversos filósofos advogando o uso "naturalista" da palavra ontologia; por exemplo, no sitio sobre ontologia da Universidade do Estado de New York em Buffalo, encontramos a seguinte afirmativa: "a ontologia não é uma disciplina que existe separada e independentemente das outras disciplinas científicas, e também dos demais ramos da filosofia. Antes, a ontologia deriva a estrutura geral do mundo; ela obtém a estrutura do mundo como ele realmente é a partir do conhecimento embutido em outras disciplinas (...). A ontologia tem derivado a estrutura do mundo a partir de outras disciplinas que descrevem a realidade, e tem, portanto, se pautado na linguagem dessas outras disciplinas." (Suny-Buffalo, 2012).

Apesar de levarmos em conta essas observações, aqui não desenvolveremos completamente este ponto de vista, o qual deveria ser discutido em pormenor, mas assumiremos a posição de que é legítimo investigar a ontologia de uma teoria (ou associada a uma teoria), e que esse tipo de investigação pode ser relacionado com o estudo da ontologia no sentido tradicional, conforme discutimos acima. O estudo da ontologia de uma teoria tem um caráter localizado e específico, enquanto que a ontologia, em seu sentido tradicional, tem um caráter a priori e pretende-se universal. Assim, não se tem a pretensão de que a ontologia de uma teoria descreva a estrutura geral de tudo o que há, abrindo desse modo a possibilidade para a existência de outros tipos de entidades além daquelas investigadas pelas teorias científicas particulares. Sob esta ótica, podemos até mesmo ter situações em que a mesma teoria pode admitir ontologias distintas, bastando para isso que seja compatível com categorias ontológicas distintas. ${ }^{\mathbf{8}}$ Esta proposta tem a clara vantagem de ser compatível com a multiplicidade de teorias científicas, seu pluralismo metodológico e até mesmo ontológico (cf. French \& Krause, 2006).

Podemos tornar alguns aspectos da tese mais claros se, seguindo Rohrlich (1999), observarmos que diferentes teorias fornecem descrições diferentes dos mesmos aspectos da realidade. Começaremos notando que diferentes teorias podem tratar daquilo que Rohrlich chama de diferentes níveis cognitivos, cada um deles tratando de uma escala particular de comprimento, tempo e energia. Essas teorias, além disso, utilizam suas próprias metodologias, seus conceitos e ferramentas. Cada uma delas fará um in-

8 Um dos exemplos mais interessantes disso seria a própria mecânica quântica, que é compatível com uma ontologia de indivíduos e uma ontologia de não indivíduos. Neste caso, categorias distintas estão envolvidas em cada uma das ontologias (indivíduos, não indivíduos), mas ambas também possuem algumas categorias em comum, como a dos universais, em um sentido específico em que os objetos quânticos podem ser assumidos como possuidores de propriedades. 
ventário diferente do mundo, de acordo com o modo como cada uma dessas características é satisfeita. Rohrlich refere-se às diferentes formas como supostos amigos cientistas descrevem o seu gato; para o biólogo, trata-se de uma muito complicada coleção de diferentes células em interação; o bioquímico diz que o gato é um amontoado complexo de compostos orgânicos, como proteínas, aminoácidos etc. $\mathrm{O}$ amigo físico tem opinião diferente, dizendo que o gato é uma coleção de átomos ligados para formar os compostos de que falam os anteriores, e o físico de partículas vai ainda mais longe, sustentando que mesmo os átomos são compostos de quarks, gluons, elétrons e outras partículas. O que de fato é o gato? Impossível saber. Se aceitamos isso, não precisamos comprometer-nos com a tese de que há uma única ontologia para o mundo, a "verdadeira", dada talvez pela teoria final ideal (se isso faz sentido), mas podemos deixar essa questão em aberto e investigar as diferentes ontologias fornecidas pelas diversas teorias científicas, ou seja, os diferentes modos como as diversas teorias nos contam como é o mundo. Porém, como esperamos já haver deixado claro, isso não impede que se defenda uma tese reducionista, sustentando que há uma teoria verdadeira última, a qual nos dirá exatamente do que o mundo é realmente formado, mas não vamos comprometer-nos com essa posição. Outra vantagem da abordagem proposta aqui radica no fato de que com ela evitamos a possível objeção, que surge naturalmente quando se identificam os dois sentidos da palavra "ontologia" distinguidos acima, de que a ontologia, devendo investigar os aspectos últimos da realidade, deveria concentrar-se apenas nas teorias mais sofisticadas ou nas "últimas" teorias, já que elas dariam uma descrição "melhor" e mais precisa da realidade. Nesse caso, estudar a ontologia da mecânica quântica ortodoxa pareceria sem propósito, já que esta teoria possui limitações bem conhecidas e foi superada em alguns domínios pelas teorias quânticas de campos (e nas tentativas de elaborar uma teoria da gravitação quântica). No entanto, a objeção perde seu efeito quando consideramos a distinção feita acima, em que entendemos ontologia em dois sentidos, e reconhecemos que cada teoria aplica-se a um determinado nível cognitivo, que merece ser investigado do ponto de vista filosófico e, talvez, com finalidades pragmáticas. Que este é realmente o caso pode ser constatado ao levar-se em conta que ainda há uma série de experimentos importantes sendo feitos que se baseiam apenas na mecânica quântica ortodoxa, revelando, assim, sua importância e relevância. Para constatar isso, basta acompanhar os experimentos realizados em Viena por Anton Zeilinger e sua equipe (cf. Wien Universität, 2011).

\subsection{LóGIGAS}

Como a lógica entra na formulação das teorias e se relaciona com o tipo de ontologia com a qual ela pode estar comprometida? Conforme mencionamos anteriormente, o 
critério de compromisso ontológico de Quine aplica-se a teorias formuladas em uma linguagem "regimentada", ou seja, uma linguagem formalizada, que ele entendia que deveria ser a do cálculo clássico de primeira ordem sem identidade, satisfazendo mais alguns requisitos, como, por exemplo, não possuir constantes individuais, símbolos para operações e ter apenas um número finito de símbolos para predicados e relações. Tal tipo de restrição, todavia, não nos permitiria expressar o compromisso ontológico com muitos tipos de objetos que poderiam estar implicados por algumas teorias científicas. Conforme observa da Costa (2008, p. 141-54), a lógica clássica comprometenos com uma determinada imagem idealizada de mundo, que seria estática, na qual existiriam substâncias fixas às quais atribuímos propriedades, entre outras características. Como esta imagem nem sempre é a mais adequada para expressarmos as categorias ontológicas com as quais acreditamos que a teoria esteja comprometida, devemos (como sugere da Costa) relativizar o critério de Quine a uma determinada lógica e a uma determinada linguagem.

Ainda seguindo a tese de da Costa, lógicas diferentes podem comprometer-nos com diferentes tipos de entidades e, assim, serem compatíveis com diferentes categorias ontológicas. Por exemplo, uma lógica clássica de segunda ordem comprometenos com propriedades, uma lógica paraconsistente que fundamenta uma teoria de conjuntos pode comprometer-nos com objetos como um conjunto de Russell ou, se desejamos ir mais longe, com objetos contraditórios em geral, permitindo que se fundamente uma ontologia a la Meinong, que admite a existência até mesmo de objetos contraditórios, como o círculo quadrado ${ }^{9}$ Assim, a restrição à lógica clássica e de primeira ordem pode ser relaxada com muito proveito para o filósofo interessado em metafísica, abrindo a possibilidade de exploração de lógicas de ordem superior e teorias de conjuntos tanto clássicas quanto não clássicas, e a questão aqui é encontrar uma lógica que seja mais adequada ao tipo de objetos com os quais se acredita que a teoria em questão esteja comprometida. Por enquanto, temos uma ontologia, tomada no sentido tradicional, a qual nos informa quais categorias de objetos existem e, em segundo lugar, a investigação científica que de certa forma atualiza algumas dessas categorias, que supostamente devem refletir-se também na lógica escolhida para falar desses objetos e, então, a flexibilização do critério de Quine feita por da Costa começa a aparecer e faz perfeito sentido.

No entanto, apenas essa relativização do critério de Quine não basta. Conforme devemos reconhecer, os valores das variáveis, ou seja, os itens com os quais nos com-

9 Por "conjunto de Russell", entendemos a coleção de todos as coleções que não pertencem a si mesmas, como, por exemplo, o conjunto dos gatos; em símbolos, $\mathrm{R}=\{x: x \notin x\}$. Tal coleção não é um "conjunto" da maior parte das teorias de conjuntos (supostas consistentes), mas "existe" em algumas teorias paraconsistentes de conjuntos. 
prometemos, podem ser vistos como estando representados pelos objetos do domínio de uma estrutura na qual interpretamos a teoria (cf. Krause: Arenhart \& Moraes, 2010). Porém, se assumirmos isso, teremos que aceitar que devemos considerar a metalinguagem na qual elaboramos a semântica de nossas teorias. Insistamos nisso: como usualmente admitem os filósofos quando consideram essas questões (infelizmente, nem sempre eles se apercebem desses importantes detalhes), trabalhamos em alguma matemática; via de regra, por facilidade e familiaridade, optamos por utilizar uma teoria de conjuntos como metamatemática e, então, ficamos a mercê dessa teoria, de sua capacidade expressiva e de suas hipóteses. Isso pode gerar problemas, pois, suponhase que nos comprometemos com uma lógica distinta da clássica para formular uma teoria - por exemplo, a teoria do átomo de Bohr, que aparentemente é inconsistente (Vickers, 2009) - e que utilizamos uma teoria de conjuntos "clássica" como metalinguagem - por exemplo, a teoria ZFG, Zermelo-Fraenkel como axioma da escolha -, na qual são elaboradas as considerações semânticas. Desse modo, ainda que a linguagemobjeto (com sua lógica) deveria supostamente contemplar algo como a presença das contradições na teoria de Bohr, estaremos reintroduzindo algumas noções "clássicas", como a suposta ausência de contradições, via a metamatemática utilizada, no caso, a teoria de conjuntos. Como impedir que estas noções, que não desejamos, retornem "pela porta dos fundos"? Ou seja, como coadunar o que desejamos expressar em nossa teoria com a metamatemática?

O próprio da Costa formulou uma exigência nesse sentido: a metalinguagem na qual elaboramos a semântica de um sistema de lógica deve estar de certo modo de acordo com os pressupostos dessa lógica (cf. da Costa, 2008; da Costa et al., 1995). Assim, por exemplo, para elaborarmos a semântica para uma lógica intuicionista, procurando refletir, pelo menos em parte, a filosofia intuicionista, devemos utilizar uma metalinguagem intuicionista, o que não impede que alternativamente elaboremos uma semântica para a lógica intuicionista utilizando, obviamente, a lógica e a matemática clássicas, como é aliás usual, e assim por diante. Para a teoria do átomo de Bohr, deveríamos utilizar, na metamatemática, uma teoria paraconsistente de conjuntos. Isso garantiria, idealmente, que o sistema de lógica em questão não pressupusesse em sua formulação as noções de qualquer sistema diferente. Tal exigência já foi discutida em outro lugar, sob o nome de princípio de consistência semântica de von Weizsäcker-da Costa (cf. Krause \& Arenhart, 2010, p. 10), uma vez que Carl Von Weizsäcker discutiu anteriormente o assunto de forma bastante semelhante. Seguindo o critério, a semântica seria formulada de modo mais adequado para captar as categorias que desejamos empregar em nossa ontologia e, consequentemente, os objetos com os quais a teoria irá comprometer-se terão as características desejadas, quais sejam, aquelas que nos levaram a adotar uma lógica distinta da clássica para captá-las formalmente. 
Assim, temos três aspectos a serem considerados relativamente à ontologia:

(1) a ontologia pode ser considerada em seu sentido tradicional, que nos informaria sobre as categorias de objetos que podem existir;

(2) a ontologia pode também ser considerada no sentido naturalizado, que buscaria empregar algumas dessas categorias para informar sobre o tipo de objetos com o qual uma determinada teoria científica está comprometida e, por fim,

(3) a metamatemática, que deverá estar de acordo com a ontologia nesse segundo sentido, de forma que nossos compromissos ontológicos possam ser adequadamente formulados, ou seja, que os aspectos semânticos estejam de acordo com os sintáticos.

Tendo formulado essas noções de forma bastante geral, passaremos agora a argumentar que a mecânica quântica pode ser vista como comprometida com a possibilidade da admissão de objetos indistinguíveis que podem ser considerados como não indivíduos. Assim, seguindo o que foi discutido, a metamatemática que fundamenta tal concepção deverá ser consoante com aquela que será utilizada para falar das entidades da teoria. Teoria e metateoria devem andar em consonância. Notemos que isto envolve atacar o problema da ontologia no sentido naturalizado, pois estamos argumentando que uma teoria nos compromete com certo tipo de objetos e, também, com o problema de encontrar a lógica mais adequada para expressar esse tipo de compromisso. O trabalho no campo da ontologia no sentido tradicional, por sua vez, envolverá discutir a possibilidade de que existam objetos que não são indivíduos, objetos que sejam indistinguíveis etc. Sem mais pormenores, passamos então para a discussão da indistinguibilidade.

\section{IndistinguibILIDADE E IMPERMUTABILIDADE}

\subsection{IndistinguibiLidade}

Como já observamos na introdução, um dos modos mais simples de entender a indistinguibilidade consiste em tomá-la como uma relação entre objetos que partilham propriedades ou atributos. Usualmente, em discussões sobre partículas indistinguíveis, utilizamos a restrição de que as propriedades em questão sejam apenas as intrínsecas, ou independentes do estado. Nesse sentido, como já comentado, as 
partículas clássicas, isto é, aquelas descritas pela física clássica, também podem ser indistinguíveis. No entanto, estas últimas costumam ser consideradas como indivíduos, se assumirmos a hipótese de que são, como já foi dito acima, impenetráveis. Ou seja, na física clássica, pode-se falar em trajetórias individuais e a localização espaço-temporal é um fator essencial em sua distinção. Qual é então o problema com as partículas quânticas? Por que, além de serem indistinguíveis, podem ser consideradas não indivíduos? Ressaltamos, mais uma vez, que essa é uma das possibilidades; como mostrado em French e Krause (2006), a mecânica quântica não relativista comporta também uma ontologia de indivíduos, mas com o ônus de introduzir restrições nos estados acessíveis e nos observáveis a serem considerados, conforme veremos resumidamente abaixo.

Para entendermos melhor o papel atribuído à indistinguibilidade e à identidade na mecânica quântica, convém voltarmos um pouco no tempo e analisar uma tentativa de Boltzmann de derivar, a partir da mecânica clássica, uma prova de que um gás deve evoluir para o estado de equilíbrio a partir de um estado inicial qualquer, fornecendo, assim, uma fórmula para a entropia de um gás ideal. Esta foi uma tentativa de "demonstrar" a segunda lei da termodinâmica, e ficou conhecida como o teorema-H de Boltzmann (cf. Kuhn, 1987, cap. 2). Boltzmann abordou o assunto no contexto de sua busca para provar uma lei de distribuição molecular apresentada previamente por Maxwell, o que ele fez de dois modos diferentes (cf. French \& Krause, 2006 p. 25-6; Kuhn, 1987, cap. 2). Um deles, o que nos interessa aqui, envolve investigar as possíveis distribuições de partículas em estados possíveis. Ao propor sua demonstração, Boltzmann apelou para uma forma de distribuição chamada atualmente de estatística de Maxwell-Boltzmann. Segundo essa estatística, para tomarmos um exemplo, se tivermos dois objetos, rotulados 1 e 2, e desejarmos saber de quantos modos distintos podemos distribuir esses objetos em dois estados rotulados $A$ e $B$, teremos as seguintes opções (aqui denotamos por $A(1)$ o fato de que a partícula 1 está no estado $A$, e assim por diante):
(1) $A(1) A(2)$
(2) $B(1) B(2)$
(3) $A(1) B(2)$
(4) $A(2) B(1)$

Se assumirmos a hipótese da equiprobabilidade das possíveis distribuições - o que não é algo óbvio -, teremos que cada um dos casos (1) a (4) tem a probabilidade ${ }^{1 / 4}$ de ocorrer. $\mathrm{O}$ que nos interessa mais especificamente é o fato de que nos casos (3) e (4), que diferem por serem cada um deles uma permutação das partículas, contam como 
dois casos distintos. É precisamente a esse fato que usualmente se apela para fundamentar a afirmação de que as partículas clássicas são indivíduos; apesar de eventualmente possuírem as mesmas propriedades, elas dão origem a situações distintas quando são permutadas. Assim, se partilham suas propriedades (com exceção das de localização espaço-temporal), sua individualidade não pode ser atribuída a uma dessas propriedades, ou a um conjunto delas, mas deve advir de algo a mais, alguma forma de substrato. A essa forma de individualidade, Heinz Post chamou de "individualidade transcendental", pois seria conferida por algo que "transcende" os atributos das partículas (cf. French \& Krause, 2006).

Além disso, a fórmula clássica para a entropia $\mathrm{S}$ para um gás simples, composto de $\mathrm{N}$ partículas de massa $m$ em um volume $\mathrm{V}$, baseando-se nessa estatística, é a seguinte:

$$
\mathrm{S} / k \mathrm{~N}=\ln \left(\mathrm{V} / \Lambda^{3}\right)+3 / 2+\ln \alpha / \mathrm{N}
$$

em que $k$ é a constante de Boltzmann, ln o logaritmo natural, $\mathrm{T}$ a temperatura, e $\Lambda$ é o comprimento de onda termal. Aqui, $\alpha$ é um número que, na formulação original, assumia o valor 1 . No entanto, a fórmula obtida, quando utilizamos este valor, incorre em problemas se desejamos que a entropia seja extensiva. Para entender melhor a dificuldade, vamos supor que temos dois volumes, cada um deles contendo um gás de entropia $\mathrm{S}$, separados por uma barreira móvel, e que os gases em cada um dos volumes são do mesmo tipo. Se retirarmos a barreira, permitindo que se misturem os gases contidos nos dois volumes, teremos que idealmente a entropia do sistema assim composto deveria ser a soma das entropias dos dois sistemas originais, ou seja, $2, \mathrm{~S}$, e é exatamente isso que a extensividade da entropia nos garante.

Todavia, na fórmula derivada acima, $\operatorname{com} \alpha=1$ teremos que a entropia não é extensiva, pois ela resulta ser um pouco maior do que ${ }_{2} \mathrm{~S}$. Essa é, grosso modo, uma das formulações do famoso paradoxo de Gibbs. A forma usual que se empregou para resolvêlo foi modificar o valor de $\alpha$, assumindo que vale $1 / \mathrm{N}$ !. A fórmula obtida desse modo é a chamada equação de Sackur-Tetrode para a entropia, e nos dá o resultado correto, em que a entropia é extensiva. Mas qual é o efeito de se tomar esse valor para $\alpha$, ou, em outras palavras, de se dividir tudo por N!? Aqui entra a indistinguibilidade de modo essencial. $\mathrm{O}$ argumento usualmente empregado para justificar esse passo consiste em afirmar que as partículas não devem ser distinguíveis no sentido de que permutações possam ser contadas como possibilidades distintas e, assim, as permutações de partículas indistinguíveis presentes na estatística de Maxwell-Boltzmann (as situações (3) e (4) acima) deveriam ser contadas apenas uma vez. Ou seja, não pode haver distinção entre as partículas. Deste modo, ao dividirmos a fórmula por N!, fatoramos a ex- 
pressão que nos dá a entropia, e as permutações não contam mais como indicando casos distintos.

Mas, agora, temos aparentemente dois sentidos distintos da palavra indistinguibilidade: por um lado, a posse em comum de todas as propriedades intrínsecas e, por outro lado, a fatoração da estatística cancelando as permutações ou, se preferirmos, estabelecendo que as permutações não possuem efeito, de modo que não dão origem a estados distintos. Neste segundo sentido, diz-se que a entropia só satisfaz a condição de extensividade, se assumimos que as partículas são indistinguíveis, no sentido de que as permutações não contam para revelar estados distintos. Será que o paradoxo de Gibbs de certa forma garante que as partículas devem ser indistinguíveis nesse segundo sentido?

Vamos seguir Bitbol (1996, p. 317), que chama de impermutabilidade a essa segunda forma de indistinguibilidade. Assim, a questão é saber se o paradoxo de Gibbs mostra que as partículas são realmente impermutáveis. A disputa sobre o que nos ensina o paradoxo não será tema abordado aqui, mas adotaremos a proposta apresentada por French e Krause (2006, p. 145-6), que sustentam uma interpretação mais modesta do paradoxo. Ele nos mostra que as partículas são quânticas por natureza e, assim, para obtermos os resultados corretos, devemos voltar-nos para a mecânica quântica, onde as estatísticas são diferentes daquela de Maxwell-Boltzmann e, desse modo, não precisamos lançar mão de recursos como a fatoração da fórmula para a entropia. Ou seja, devemos deixar o campo clássico de lado, em prol de um novo domínio, regido pelas leis da física quântica. Vejamos em que consiste a impermutabilidade nas estatísticas comuns a tal domínio quântico.

\subsection{IMPERMUTABILIDADE E MECÂNICA QUÂNTICA}

Na mecânica quântica não relativista, as permutações de partículas indiscerníveis não devem contar como dando origem a estados distintos. No entanto, a impermutabilidade não está assumida desde o início, ou seja, não se parte da suposição da impermutabilidade, sendo necessário introduzir artifícios para simular, na matemática padrão e na lógica clássica, a indiscernibilidade, como no caso da derivação da equação de Sackur-Tetrode, vista acima. Vejamos isso de outro modo. Na física quântica, não temos apenas uma estatística, mas duas: uma para as partículas classificadas como bósons, a estatística de Bose-Einstein (BE), e outra para as partículas classificadas como férmions, chamada de estatística de Fermi-Dirac (FD). A diferença está em que os férmions obedecem ao chamado princípio de exclusão de Pauli, segundo o qual, falando por alto, dois férmions não podem ocupar o mesmo estado. Para ilustrar estas estatísticas, 
vamos novamente considerar o caso de duas partículas, rotuladas 1 e 2, e dois estados, $A$ e $B .{ }^{10}$ Eis os diferentes modos em que podemos distribuí-las:
(1) $A(1)$ e $A(2)$
(2) $B(1)$ e $B(2)$
(3) $A(*)$ e $B(*)$

Aqui, se assumirmos, como se faz usualmente, que cada uma das distribuições é equiprovável, teremos para os bósons que cada um dos casos (1) a (3) tem a probabilidade de 1/3 de ocorrer. Para os férmions, por obedecerem ao princípio de exclusão de Pauli, apenas (3) é um estado possível, e terá a probabilidade 1 de ocorrer. Em (3), colocamos “*”, em vez de 1 ou 2 para simbolizar precisamente o fato de que as permutações de partículas não geram estados diferentes. Este é um problema da linguagem comum, na qual expressamos essa distribuição; uma de suas limitações consiste justamente no fato de que ela faz uso preponderante de um mecanismo de rotulação para que possamos fazer referência aos objetos considerados, mesmo quando está em questão a possibilidade desse próprio mecanismo de referência através da nomeação e rotulação.

O próximo passo é vermos como podemos representar essas situações no formalismo da mecânica quântica ortodoxa. Como temos duas partículas indistinguíveis, vamos utilizar o mesmo espaço de Hilbert $\mathbf{H}$ associado a ambas, e descrever seus estados através dos vetores do produto tensorial desse espaço consigo mesmo. Teremos os seguintes casos, onde, como é usual, suprimimos o símbolo de produto tensorial entre dois vetores:
(1) $\left|1^{\mathrm{A}}\right\rangle\left|2^{\mathrm{A}}\right\rangle$
(2) $\left|1^{\mathrm{B}}\right\rangle\left|2^{\mathrm{B}}\right\rangle$
(3) $C\left(\left|1^{\mathrm{A}}\right\rangle\left|2^{\mathrm{B}}\right\rangle \pm\left|2^{\mathrm{A}}\right\rangle\left|1^{\mathrm{B}}\right\rangle\right)$

Em (3), $C$ é uma constante de normalização. Para bósons, tomamos o sinal +, e para férmions, o sinal - . Assim, o fato de que as permutações não são contadas como dando origem a estados distintos é obtido com a utilização de vetores de estado simétricos (bósons) e antissimétricos (férmions). Devemos notar que o estado representado em (3) não é a "identificação" dos estados assimétricos caracterizados por $\left|1^{\mathrm{A}}\right\rangle\left|2^{\mathrm{B}}\right\rangle$ e $\left|2^{\mathrm{A}}\right\rangle\left|1^{\mathrm{B}}\right\rangle$. Estes estados geram um subespaço distinto daquele gerado pelos 
vetores em (3), e é ortogonal a eles. Desse modo, vê-se claramente o truque: iniciamos com objetos discernidos pelos seus rótulos (ou nomes, se quisermos), e então assumimos que somente certos estados contam, exatamente aqueles que são consoantes com a indiscernibilidade. Mas a distinção inicialmente feita (por necessidade da linguagem e da matemática utilizadas) permanece presente nos bastidores, estando apenas escondida. A física pode, como de fato ocorre, funcionar muito bem, mas a filosofia correspondente parece-nos um tanto artificial.

Um fato deve ser observado. Poder-se-ia argumentar que mesmo partículas indiscerníveis seriam distinguíveis, se localizadas em regiões distintas e disjuntas, digamos, uma aqui em Florianópolis, descrita pelo vetor $|\mathrm{F}\rangle$, e outra em Paris, dada por $|\mathrm{P}\rangle$. Acontece que, como discutimos acima, o vetor assimétrico $|\mathrm{F}\rangle|\mathrm{P}\rangle$ (ou alternativamente, $|\mathrm{P}\rangle|\mathrm{F}\rangle)$ que representaria essa dupla situação, não é considerado como descrevendo uma situação física aceitável em física quântica; em vez dele, devemos considerar vetores simétricos ou antissimétricos, como em (3) acima. Com eles, nenhuma particularização é possível, apesar de uma das partículas estar aqui e a outra em Paris, não podemos saber qual é qual, e essa é uma das características fundamentais da física quântica, a qual contraria fortemente a noção intuitiva de indivíduo. ${ }^{\mathbf{1 1}}$

Tecnicamente, garantimos que as permutações não são observáveis através do chamado "postulado de indistinguibilidade" (que é introduzido adhoc), segundo o qual, grosso modo, os operadores $\mathrm{O}$ representam observáveis, quando aplicados aos vetores de estados, devem sempre comutar com os operadores de permutação:

$$
[\mathrm{PO}, \mathrm{OP}]=\mathrm{PO}-\mathrm{OP}=\mathrm{O}
$$

Aqui, como dissemos, O é um operador hermitiano que representa um observável e P representa um operador de permutação de rótulos de partículas. Para uma expressão equivalente, onde $\psi$ representa um estado de duas partículas indistinguíveis no produto tensorial de $\mathbf{H}$ consigo mesmo, temos:

$$
\langle\psi|\mathrm{O}| \psi\rangle=\langle\mathrm{P} \psi|\mathrm{O}| \mathrm{P} \psi\rangle
$$

Ou seja, o valor esperado para a medida do observável $\mathrm{O}$ antes e depois de permutarmos as partículas é o mesmo e, assim, qualquer permutação não pode ser "observável” (dar origem a situações físicas distintas). Claro, este resultado também se baseia no fato de que, uma vez em um estado com determinado tipo de simetria, os operadores

11 Novamente, a questão básica aparece: se admitirmos que uma distinção é possível, estaremos aceitando que alguma forma de variável oculta pode estar em jogo. As teorias de variáveis ocultas têm muitos defensores, mas sabe-se de seus problemas, como os de que tais teorias devem ser contextuais e não locais (cf. Pessoa Junior, 2005, 2006). 
"lícitos" não nos levam a outros tipos de simetria, ou seja, não passamos de um estado simétrico para um antissimétricos ou vice-versa.

Este postulado, PI, está no centro das discussões sobre a nãoindividualidade das partículas quânticas. Conforme o apresentamos, ele parece implicar que nada pode distinguir as partículas em questão, devido justamente a sua impermutabilidade. Assim, alguns autores (como Heisenberg, Schrödinger, Weyl, Mary Hesse, Max Born) sustentaram que elas, de alguma forma, teriam perdido sua individualidade, e que as partículas não poderiam mais ser identificáveis. Todavia, existe outro modo segundo o qual podemos entender esse postulado, e que pressupõe uma leitura mais fraca de PI, segundo a qual alguns estados (os assimétricos) não são acessíveis às partículas. Grosso modo, segundo essa forma de ver o postulado, as partículas poderão ser diferenciadas, pelo menos em princípio, mesmo que essa diferença não possa ser observada. Em tal caso, elas podem ser consideradas como indivíduos em alguma acepção e, assim, a mecânica quântica é compatível também com uma ontologia de indivíduos em adição àquela de não indivíduos. No primeiro caso, tem-se argumentado convincentemente que as partículas violam o princípio da identidade dos indiscerníveis, pois podem ser indiscerníveis e assim, sua individualidade (se supusermos que elas a têm) deve ser fundamentada em algum tipo de princípio que transcende as propriedades dos particulares, alguma forma de substrato (cf. French \& Krause, 2006, cap. 4).

Aqui, interessa perseguir as consequências de adotar-se a primeira leitura de PI aqui proposta, e esclarecer como isso nos leva a uma forma de não reflexividade. Se não indivíduos são objetos que não figuram com sentido em relações de identidade ou diferença, a identidade deixa de poder ser aplicada a esses objetos. $O$ fato de serem impermutáveis parece acabar com muitas das principais características que um indivíduo deveria ter, como poder ser rotulado, nomeado e, pelo menos em princípio, identificado em diferentes situações como sendo aquele indivíduo, tal como no caso da formiga mencionada acima. Assim, somos levados à chamada perda de individualidade das partículas. Porém, se adotarmos uma perspectiva metafísica de não indivíduos, não há propriamente o que ser perdido, pois em princípio essas entidades seriam $a b$ ovo destituídas de identidade. Esta parece ser uma possibilidade bastante plausível. Mas, ao fazer filosofia da ciência, no nosso entender, não se deve simplesmente especular; devemos tentar tornar nossas idéias precisas e compatíveis com a ciência propriamente. Assim, no restante deste artigo, vamos ver como as noções discutidas podem ser captadas em um sistema de lógica desenvolvido especificamente para tratar com não indivíduos. ${ }^{12}$

12 Neste trabalho, como já ressaltamos, estamos entendendo o termo "lógica" em um sentido amplo, envolvendo não apenas um cálculo de proposições e de predicados de primeira ordem (clássicos ou não), mas também os sistemas de lógica de ordem superior e as chamadas "grandes lógicas", que envolvem teorias de conjuntos e de categorias. 


\section{LÓGICA NÃO REFLEXIVA}

A partir de agora, faremos um resumo das noções básicas da teoria de quase conjuntos, mostrando como ela incorpora de modo natural as características das partículas quânticas expressas acima. Por brevidade, chamaremos a teoria de $Q$. Essa teoria, que, na verdade, tem várias formulações, foi proposta por um dos autores deste artigo em 1990 (cf. French \& Krause, 2006).

\subsection{Linguagem E NOÇõES BÁSicAS}

A lógica subjacente à teoria da qual trataremos possui, formalmente, os mesmos postulados e símbolos lógicos que a lógica clássica sem o símbolo de identidade, apesar de comportar-se diferentemente de um ponto de vista semântico (ver o princípio de consistência semântica discutido acima). A linguagem da teoria é composta dos seguintes símbolos não lógicos (as demonstrações aqui indicadas, mas não exibidas, podem ser vistas em French \& Krause, 2006):

(1) Três símbolos de predicados unários, Z, m e M, onde $\mathrm{m}(\mathrm{x})$ e $\mathrm{M}(\mathrm{x})$ podem ser lidos intuitivamente como ‘x é um microátomo' e ‘x é um macroátomo', respectivamente. $\mathrm{Z}(\mathrm{x})$ indica que $\mathrm{x}$ é um conjunto;

(2) dois símbolos de predicados binários, $\in$ (pertinência) e $\equiv$ (indistinguibilidade), este último lê-se '... é indistinguível de __, onde os espaços são ocupados por termos individuais;

(3) um símbolo funcional unário qc( ), tal que qc(x) denotará o quase cardinal de $\mathrm{x}$, cujos axiomas estendem a noção usual de cardinal para quase conjuntos em geral.

A teoria de quase conjuntos $Q$ é baseada em axiomas semelhantes aos da teoria ZFU (Zermelo-Fraenkel com Urelemente), mas admite dois tipos de átomos, distinguidos pelos predicados apresentados em (1) acima. Intuitivamente, temos os macroátomos, que chamaremos de $M$-átomos, que se comportam como os átomos de ZFU, ou seja, são como os átomos "clássicos", e os microátomos, que chamaremos de m-átomos, os quais intencionalmente representam objetos que podem ser indistinguíveis, para os quais as noções de identidade e de diferença não se aplicam. Assim, quando precisarmos falar que temos "dois" objetos, isso nos conduzirá a sua discernibilidade, e não a sua diferença. Todos, no entanto, podem estar relacionados pela relação primitiva de indistinguibilidade e essa noção, quando aplicada aos $\mathrm{M}$-átomos, formalmente 
coincide com a identidade usual, dita identidade extensional, que será apresentada abaixo. Começamos exigindo que esses dois tipos de objetos sejam distintos: ${ }^{\mathbf{1 3}}$

$$
\text { (Q1) } \forall \mathrm{x}(\neg \mathrm{m}(\mathrm{x}) \vee \neg \mathrm{M}(\mathrm{x})) \text {. }
$$

Além desses dois tipos de átomos, introduzimos por definição o símbolo Q, onde Q(x) diz que x é um quase conjunto (que chamaremos de q-set). Por definição, um quase conjunto é um objeto da teoria que não é nenhum dos átomos, de modo semelhante ao que ocorre em ZFU, onde há átomos e objetos que não são átomos, os conjuntos de ZFU propriamente ditos. Com isso, também podemos descartar o caso em que os átomos tenham elementos:

Def. [x é um q-set] $\mathrm{Q}(\mathrm{x})={ }_{\text {Def }} \neg \mathrm{m}(\mathrm{x}) \wedge \neg \mathrm{M}(\mathrm{x})$.

$$
\text { (Q2) } \forall \mathrm{x} \forall \mathrm{y}(\mathrm{x} \in \mathrm{y} \rightarrow \mathrm{Q}(\mathrm{y}))
$$

Os q-sets, por sua vez, podem ser "classificados" de acordo com os tipos de elementos que neles ocorrem. Assim, podemos ter q-sets:

(a) puros: os que contêm apenas m-átomos indistinguíveis (esta não é a terminologia original, mas será aqui utilizada);

(b) standard: q-sets cujo fecho transitivo não contém m-átomos, e que se comportam como os conjuntos clássicos de ZFU, correspondendo aos q-sets que satisfazem o predicado $\mathrm{Z}$ da linguagem apresentada acima, podendo por isso ser chamados apenas de "conjuntos";

(c) q-set usual: pode conter m-átomos, M-átomos, e outros q-sets como elementos.

É importante notar que os q-sets standard são "cópias" de conjuntos clássicos de ZFU na teoria de quase conjuntos, ou seja, é possível obtê-los através de uma tradução da linguagem de ZFU na teoria de quase conjuntos. Dito de outro modo, a teoria de quase conjuntos que apresentamos aqui "contém" a teoria ZFU, de modo que toda a matemática que pode ser desenvolvida em ZFU pode ser também desenvolvida na teoria que estamos considerando. 


\subsection{IDENTIDADE E INDISTINGUIBILIDADE}

A relação de identidade desempenha papel fundamental na nossa busca por um sistema que capte a noção de não indivíduo conforme apresentada acima. Estamos concebendo não indivíduos na acepção, já explicada anteriormente, de objetos que não entram com sentido nas relações de identidade ou diferença. Para formalizar esta noção em $Q$, definimos “= $"$ ", a igualdade extensional, a relação de identidade nessa teoria, pela fórmula:

$$
\mathrm{w}={ }_{\mathrm{E}} \mathrm{t}={ }_{\operatorname{Def}}[(\mathrm{Q}(\mathrm{w}) \wedge \mathrm{Q}(\mathrm{t}) \forall \mathrm{z}(\mathrm{z} \in \mathrm{w} \leftrightarrow \mathrm{z} \in \mathrm{t})) \vee(\mathrm{M}(\mathrm{w}) \wedge \mathrm{M}(\mathrm{t}) \wedge \forall \mathrm{z}(\mathrm{w} \in \mathrm{z} \leftrightarrow \mathrm{tz}))]
$$

A igualdade extensional funciona do mesmo modo que a identidade clássica para os "objetos clássicos" da teoria, possuindo todas as suas propriedades, mas não pode fazer parte de enunciados quando se trata dos $\mathrm{m}$-átomos, os quais representam as partículas quânticas. É importante enfatizar isso. A lógica subjacente à teoria de quase conjuntos, a qual se aplica a todas as entidades que não envolvam m-átomos, é a lógica clássica sem identidade. Assim, o único tipo de igualdade que se pode afirmar nesta teoria é a igualdade extensional, que, no caso de conjuntos clássicos ou M-átomos, funciona como a igualdade clássica, conforme garantido pelo seguinte axioma:

(Q3) $\forall \mathrm{x} \forall \mathrm{y}\left(\mathrm{x}={ }_{\mathrm{E}} \mathrm{y} \rightarrow(\mathrm{A}(\mathrm{x}) \rightarrow \mathrm{A}(\mathrm{y}))\right)$, onde $\mathrm{A}(\mathrm{x})$ é uma fórmula na qual $\mathrm{x}$ figura livre e $\mathrm{A}(\mathrm{y})$ é uma fórmula obtida de $\mathrm{A}(\mathrm{x})$ a partir da substituição de algumas ocorrências livres de x por y, tal que y é livre para $\mathrm{x}$ em $\mathrm{A}(\mathrm{x})$.

A reflexividade da identidade para objetos clássicos pode ser derivada como teorema a partir da definição de identidade dada anteriormente. Note-se novamente que a reflexividade da identidade não é um teorema quando se trata de m-átomos e, portanto, o sistema de lógica aqui apresentado é classificado como não reflexivo, pois a lei reflexiva da identidade não se aplica para alguns objetos. Isto, como se nota, é diferente de aceitar a negação desta lei, o que resultaria na irreflexividade da identidade.

Outra característica dos não indivíduos, como notamos acima, é a sua capacidade de poderem ser indistinguíveis. A relação de indistinguibilidade introduzida como primitiva cumpre esta função. Seus primeiros axiomas específicos são:

$$
\text { (Q4) } \begin{aligned}
& \forall \mathrm{x}(\mathrm{x} \equiv \mathrm{x})(\equiv \text { é reflexiva }) ; \\
& \forall \mathrm{x} \forall \mathrm{y}(\mathrm{x} \equiv \mathrm{y} \rightarrow \mathrm{y} \equiv \mathrm{x})(\equiv \text { é simétrica }) ; \\
& \forall \mathrm{x} \forall \mathrm{y} \forall \mathrm{z}((\mathrm{x} \equiv \mathrm{y} \wedge \mathrm{y} \equiv \mathrm{z}) \rightarrow \mathrm{x} \equiv \mathrm{z})(\equiv \text { é transitiva }) .
\end{aligned}
$$


Além disso, para os objetos “clássicos” (M-átomos e conjuntos), postulamos em $Q$ que a indistinguibilidade implica igualdade extensional (a conversa segue-se como teorema), ou seja, para quaisquer dois objetos clássicos da teoria ( $\mathrm{M}$-átomos ou conjuntos), se eles forem indistinguíveis, serão extensionalmente iguais. Para facilitar a notação, chamaremos de Ding a qualquer objeto clássico da teoria. Na sua apresentação da teoria axiomática de conjuntos em 1908, Zermelo chamou de Ding (coisa) os objetos de um suposto domínio ao qual os termos da teoria eram associados; eram eles os conjuntos e os Urelemente:

Def. [x é uma Ding] D(x) ${ }_{\text {Def }} \mathrm{M}(\mathrm{x}) \vee \mathrm{Z}(\mathrm{x})$.

$$
\left(Q_{5}\right) \forall_{\mathrm{D}} \mathrm{x} \forall_{\mathrm{D}} \mathrm{y}\left(\mathrm{x} \equiv \mathrm{y}^{\prime} ! \mathrm{x}={ }_{\mathrm{E}} \mathrm{y}\right)
$$

Em (Q5) estamos usando a quantificação restrita às Dinge, ou seja, " $\forall_{\mathrm{D}} \mathrm{x} \alpha$ " lê-se: "para todo $x$, se $\mathrm{D}(\mathrm{x})$ então $\alpha$ ". Isso nos garante que, para as Dinge, a indistinguibilidade obedece a lei da substituição de (Q3), de modo que os objetos clássicos indistinguíveis são substituíveis salva veritate. Mas para m-átomos indistinguíveis, isso não pode ser verdadeiro, já que eles não podem ser sempre intersubstituíveis, pois, nesse caso, junto com a reflexividade da relação de indistinguibilidade de $\left(Q_{4}\right)$, resultaria que a indistinguibilidade e a identidade colapsariam na mesma relação. Para evitar isso, não postulamos uma lei de substituição para a indistinguibilidade, mas antes exigimos que seja apenas uma relação de equivalência, por ( $\left.Q_{4}\right)$, que não é uma congruência, ou seja, ela não é compatível com todas as relações da teoria. Em particular, temos que para $\mathrm{m}$-átomos a indistinguibilidade não é compatível com a pertinência, ou seja, se $x$ e $y$ são m-átomos tais que $x \equiv \mathcal{y}$, e $z$ é um $q$-set, então se $x \in z$, em geral, não derivamos que $y \in z$.

\subsection{Operações elementares}

Podemos constituir novos q-sets a partir daqueles que já temos utilizando as conhecidas operações sobre coleções, como união, potência, interseção, entre outras. Começamos postulando a existência do q-set vazio, que podemos provar ser um conjunto (no sentido de satisfazer o predicado Z) e ser único (será simbolizado por $\varnothing$ ):

$$
\text { (Q6) } \exists_{Q} x \forall y(\neg y \in x) \text {. }
$$

Nossos próximos axiomas permitem introduzir a operação de união e de pares não ordenados. 


$$
\begin{aligned}
& \text { (Q7) } \forall_{\mathrm{Q}} \mathrm{x} \exists_{\mathrm{Q}} \mathrm{y} \forall \mathrm{z}\left(\mathrm{z} \in \mathrm{y} \leftrightarrow \exists_{\mathrm{Q}} \mathrm{w}(\mathrm{w} \in \mathrm{x} \wedge \mathrm{z} \in \mathrm{w})\right) \\
& \text { (Q8) } \forall_{\mathrm{Q}} \mathrm{z} \exists_{\mathrm{Q}} \mathrm{y} \forall \mathrm{x}(\mathrm{x} \in \mathrm{y} \leftrightarrow \mathrm{x} \in \mathrm{z} \wedge \mathrm{F}(\mathrm{x})) \\
& \text { (Q9) } \forall \mathrm{x} \forall \forall_{\mathrm{y}} \exists_{\mathrm{Q}} \mathrm{z}(\mathrm{x} \in \mathrm{z} \wedge \mathrm{y} \in \mathrm{z}) .
\end{aligned}
$$

A operação união de $x$ será denotada, como usualmente, por $\cup x$. (Q8) é o axioma (esquema) da separação, e o q-set y que podemos obter a partir dele, será denotado por $[\mathrm{x} \in \mathrm{z}: \mathrm{F}(\mathrm{x})]$. Nos casos em que o q-set em questão é um conjunto (satisfaz o predicado $\mathrm{Z}$ ), escrevemos, como usual, $\{\mathrm{x} \in \mathrm{z}: \mathrm{F}(\mathrm{x})\}$. Por (Q9), dados $x$ e y, existe um $q$-set $\mathrm{z}$ que os contêm como elementos. Utilizando $\mathrm{Q} 8$, $\operatorname{com} \mathrm{F}(\mathrm{w})$ definida por $\mathrm{w} \equiv \mathrm{x} \vee \mathrm{w} \equiv \mathrm{y}$, temos então o q-set $[\mathrm{w} \in \mathrm{z}: \mathrm{w} \equiv \mathrm{x} \vee \mathrm{w}=\mathrm{y}]$. Este $q$-set será denotado por $[\mathrm{x}, \mathrm{y}]_{\mathrm{z}}$, e se $\mathrm{x}$ e y forem objetos "clássicos", denota-se o par da maneira usual $\{\mathrm{x}, \mathrm{y}\}_{\mathrm{z}}$. Quando não houver problemas de ambiguidade, omitiremos o índice que indica o $q$-set de onde os elementos do par foram separados. Intuitivamente, $[\mathrm{x}, \mathrm{y}]_{\mathrm{z}}$ é o q-set cujos elementos de z, que são indistinguíveis de $\mathrm{x}$ ou de $\mathrm{y}$, e, por esse motivo, pode ser que (intuitivamente falando) possua mais do que dois elementos, ou seja, pode acontecer que contenha outros elementos além de x e y. Finalmente, define-se o unitário fraco $[\mathrm{x}]_{\mathrm{z}}$ como $[\mathrm{x}, \mathrm{x}]_{\mathrm{z}}$, que contém os indistinguíveis de $\mathrm{x}$ pertencentes a $\mathrm{z}$, e aqui novamente pode ser que tal q-set tenha mais do que um elemento.

A partir dos pares, podemos definir uma versão de pares "ordenados" na teoria de quase conjuntos da seguinte maneira $\langle\mathrm{x}, \mathrm{y}\rangle_{\mathrm{z}}{ }_{\text {def }}\left[[\mathrm{x}]_{\mathrm{z}},[\mathrm{x}, \mathrm{y}]_{\mathrm{z}}\right]$. Esta ideia pode ser generalizada, para formar triplas ordenadas, da maneira usual: $\langle\mathrm{x}, \mathrm{y}, \mathrm{z}\rangle={ }_{\operatorname{def}}\langle\langle\mathrm{x}, \mathrm{y}\rangle, \mathrm{z}\rangle$ e, assim por diante, para $n$-uplas. Daí segue-se também de maneira usual a definição de produto cartesiano:

Def. [Produto Cartesiano] $\mathrm{X} \times \mathrm{Y}={ }_{\text {def }}\left[\langle\mathrm{a}, \mathrm{b}\rangle_{\mathrm{x}} \cup_{\mathrm{y}}: \mathrm{a} \in \mathrm{X}\right.$ e $\left.\mathrm{b} \in \mathrm{Y}\right]$

Como é comum, abreviaremos por $\mathrm{X}^{\mathrm{n}}$ ao produto $\mathrm{X} \times \mathrm{X} \times \ldots \mathrm{X}$, com a operação aplicada $n$ vezes ao $q$-set X. Por fim, introduzimos o axioma das partes, e o $q$-set postulado será denotado $\wp(\mathrm{x})$, bem como o axioma do infinito:

$$
\begin{aligned}
& \text { Def. [Subqset] } \mathrm{x} \subseteq \mathrm{y}={ }_{\text {Def }} \forall \mathrm{z}(\mathrm{z} \in \mathrm{x} \rightarrow \mathrm{z} \in \mathrm{y}) . \\
& (\mathrm{Q} 10) \forall_{\mathrm{Q}} \mathrm{x} \exists_{\mathrm{Q}} \mathrm{y} \forall \mathrm{z}(\mathrm{z} \in \mathrm{y} \leftrightarrow \mathrm{z} \subseteq \mathrm{x}) . \\
& (\mathrm{Q} 11) \exists_{\mathrm{Q}} \mathrm{x}\left(\varnothing \in \mathrm{x} \wedge \forall \mathrm{y}\left(\mathrm{y} \in \mathrm{x} \rightarrow \mathrm{y} \cup[\mathrm{y}]_{\mathrm{x}} \in \mathrm{x}\right)\right)
\end{aligned}
$$


Pode-se definir também uma quase relação binária como um quase conjunto de pares ordenados, no sentido explicado, e tal definição pode ser generalizada para as relações $n$-árias. A noção de função das teorias de conjuntos usuais é generalizada para uma q-função: dados q-sets A e B, uma q-função de A em B é uma quase relação que atribui a cada $\mathrm{x} \in \mathrm{A}$ um $\mathrm{y} \in \mathrm{B}$, e ainda, dados $\mathrm{x}, \mathrm{x}^{\prime} \in \mathrm{A}$ e y, $\mathrm{y}^{\prime} \in \mathrm{B}$, se a q-função atribui $\mathrm{x}$ a y e x' a y' e $x \equiv x^{\prime}$, então $y \equiv y^{\prime}$. Esta definição é tal que, quando o domínio e contradomínio forem $q$-sets standard, recai-se no caso usual de função como conceituado nas teorias usuais de conjuntos.

\subsection{QUASE CARDINAIS E EXTENSIONALIDADE FRACA}

Como os procedimentos usuais para definir cardinalidade fazem uso da noção de identidade (através de conceitos como o de boa-ordem, correspondência um-a-um etc.), não podemos definir cardinais para todos os q-sets da maneira usual. Assim, introduziu-se o símbolo funcional unário qc para denotar o cardinal de um q-set qualquer. A principal função dos quase cardinais, no caso de coleções puras, é dar sentido para a intuição básica de que podemos ter mais de um não indivíduo, de que eles podem ser numericamente distintos, sem que expressemos isso através da relação de diferença (a negação da identidade), e sem que tenhamos que utilizar algum procedimento de contagem que faça uso de diferenças qualitativas dos objetos contados, através de um processo no qual rotulamos os objetos com números ordinais. Assim, a noção de quase cardinal é outro aspecto fundamental para captarmos a noção de não indivíduos em $Q$.

Para introduzirmos os postulados específicos desse conceito, vamos assumir que se pode (como de fato se pode) definir na parte clássica de $Q$ alguns conceitos clássicos. Temos então que:

(1) $\operatorname{card}(\mathrm{x})$ denota o cardinal de um conjunto $\mathrm{x}$ em seu sentido usual, sendo um particular ordinal definido na "parte clássica" de $Q$;

(2) Cd(x) significa que x é um cardinal; e por fim,

(3) Fin( $(x)$ indica que $x$ é um conjunto finito, com a definição usual de que existe uma bijeção entre x e um número natural. Devemos lembrar que os números naturais também são desenvolvidos na parte clássica de $Q$.

Nosso primeiro postulado garante que todo q-set possui um quase cardinal que é também cardinal, e que o quase cardinal dos conjuntos é o seu cardinal no sentido usual:

$$
\left(\mathrm{Q}_{12}\right) \forall \mathrm{x} \exists ! \mathrm{y}\left(\mathrm{Cd}(\mathrm{y}) \wedge \mathrm{qc}(\mathrm{x})={ }_{\mathrm{E}} \mathrm{y} \wedge\left(\mathrm{Z}(\mathrm{x}) \rightarrow \mathrm{y}={ }_{\mathrm{E}} \operatorname{card}(\mathrm{x})\right)\right) \text {. }
$$


Com o próximo postulado garantimos que, dado qualquer q-set com um quase cardinal $\alpha$, e dado qualquer cardinal menor do que esse cardinal, teremos um subqset deste $q$-set cujo quase cardinal é exatamente $\beta$ :

$$
(\mathrm{Q} 13) \forall_{\mathrm{Q}} \mathrm{x}\left(\mathrm{qc}(\mathrm{x})=_{\mathrm{E}} \alpha \rightarrow \forall_{\mathrm{Cd}} \beta\left(\beta \leq \alpha \rightarrow \exists_{\mathrm{Q}} \mathrm{y}\left(\mathrm{y} \subseteq \mathrm{x} \wedge \mathrm{qc}(\mathrm{y})=_{\mathrm{E}} \beta\right)\right)\right)
$$

Agora, apresentamos as relações entre qc e as operações em quase conjuntos:

$$
\begin{aligned}
& \left(\mathrm{Q}_{14}\right) \forall_{\mathrm{Q}} \mathrm{x} \forall_{\mathrm{Q}} \mathrm{y}\left(\forall \mathrm{w}(\mathrm{w} \notin \mathrm{x} \wedge \mathrm{w} \notin \mathrm{y}) \rightarrow \mathrm{qc}(\mathrm{x} \cup \mathrm{y})={ }_{\mathrm{E}} \mathrm{qc}(\mathrm{x})+\mathrm{qc}(\mathrm{y})\right) \\
& \left(\mathrm{Q}_{15}\right) \forall_{\mathrm{Q}} \mathrm{x}\left(\mathrm{qc}(\wp(\mathrm{x}))={ }_{\mathrm{E}} 2^{\mathrm{qc}(\mathrm{x})}\right)
\end{aligned}
$$

Podemos, com o auxílio da noção de quase cardinal, formular o conceito de unitário forte de um objeto. Intuitivamente falando, o unitário forte de um objeto $x$, denotado por $x$ ', será um $q$-set com apenas um elemento indistinguível de $x$. Nos casos em que $x$ é um objeto clássico, este $q$-set é o unitário usual, mas no caso em que $x$ é um mátomo, não podemos provar que o elemento do unitário forte de $x$ é o próprio $x$, pois para tanto precisamos da identidade. Assim, em $Q$, há um sentido preciso em afirmar que temos um indiscernível de $x$, sem que possamos dizer que objeto é esse.

Def. [Unitário forte] Um unitário forte de $x$ é um objeto satisfazendo a relação: $x^{\prime} \subseteq[x] \wedge q c\left(x^{\prime}\right)={ }_{\mathrm{E}} \mathbf{l}$

Nosso próximo passo é formular o axioma da extensionalidade fraca. Para isso, precisamos de algumas definições. Dizemos que os q-sets x e y são similares se não forem vazios e se cada elemento de x é indistinguível de cada elemento de y. Ainda, dizemos que $q$-sets similares que possuem o mesmo quase cardinal são $q$-similares. Com isso, podemos enunciar o axioma da extensionalidade fraca:

(Q16) Dados os q-sets x e y, se, ao passarmos o quociente desses q-sets pela relação de indistinguibilidade, tivermos que para cada elemento z de $\mathrm{x} \backslash \equiv$ existe um w em y $\equiv$ tal que z e w são q-similares, e ainda, para cada elemento w de $y \backslash \equiv$ existe um z em $\mathrm{x} \backslash \equiv$ tal que w e z são $q$-similares, então x e y são indistinguíveis, e reciprocamente (para sua expressão formal, cf. French \& Krause, 2006).

Intuitivamente, este axioma nos diz que dois q-sets x e y são indistinguíveis se e somente se possuem os mesmos tipos de objetos na "mesma quantidade". Este axioma 
permite derivar em $Q$ uma versão quase conjuntista do postulado da não observabilidade das permutações na mecânica quântica não relativista (PI). Nas teorias de conjuntos usuais, se $w \in x$, então

$$
(\mathrm{x}-\{\mathrm{w}\}) \cup\{\mathrm{z}\}=\mathrm{x} \leftrightarrow \mathrm{z}=\mathrm{w},
$$

ou seja, só podemos trocar elementos de uma coleção sem alterá-la, se trocarmos um elemento pelo mesmo elemento, devido, claro, à presença do axioma da extensionalidade. Em $Q$, pelo contrário, dado um m-átomo y, sendo y' o unitário forte y, podemos provar o seguinte teorema:

[Permutações não são observáveis] Seja x um q-set finito tal que x não possui como elementos todos indistinguíveis de $\mathrm{z}$, onde $\mathrm{z}$ é um $\mathrm{m}$-átomo tal que $\mathrm{z} \in \mathrm{x}$. Se $\mathrm{w} \equiv \mathrm{z}$ e $\mathrm{w} \notin \mathrm{x}$, existe $\mathrm{w}^{\prime}$ tal que $\left[\mathrm{x}-\mathrm{z}^{\prime}\right] \cup \mathrm{w}^{\prime} \equiv \mathrm{x}$.

O teorema garante que, se x tem $n$ elementos, e se "trocarmos" seus elementos z por correspondentes indistinguíveis w (ou seja, se realizamos a operação [x-z'] $\cup w^{\prime}$ ), então, o quase conjunto resultante permanece indistinguível daquele com o qual começamos. Em certo sentido, não importa se estamos tratando com x ou com [x-z'] $\cup$ w’. Isto significa que, em $Q$, podemos expressar que "as permutações não são observáveis", sem introduzir postulados de simetria, como ocorre no caso do tratamento usual na mecânica quântica.

Assim, expressamos em $Q$ a impermutabilidade dos m-átomos, capturando formalmente mais uma característica das partículas quânticas, bem como de outras situações em física. Por exemplo, suponha-se que temos um átomo neutro (digamos, um átomo de Helio, He). Mediante certos processos químicos, podemos ionizar o átomo, "descartando" um elétron dos dois existentes, obtendo um íon positivo $\mathrm{He}^{+}$. Depois disso, suponha que "capturamos" novamente um elétron por outro processo de ionização, obtendo novamente um átomo neutro, que é "idêntico" ao original sob todos os aspectos. Surgem as seguintes perguntas: o elétron capturado é "o mesmo" elétron que foi expelido? O primeiro átomo neutro é o mesmo átomo que o segundo átomo neutro? Essas (e outras) questões são pertinentes e estão bem formuladas, mas qualquer resposta é completamente sem sentido, pois não temos como responder quer afirmativamente, quer negativamente. $\mathrm{O}$ melhor é dizer que tanto os dois elétrons (e repare-se, podemos falar em "dois") são indiscerníveis, assim como o são os dois átomos neutros. Com isso, vemos que $Q$ é capaz de exprimir compromisso com objetos indistinguíveis, "sem identidade", no sentido de que a identidade não pode ser expressa (ou fazer sentido) para tais objetos, que podem, no entanto, ser numericamente dis- 
tintos, e impermutáveis, como acabamos de ver. Isto torna $Q$ uma teoria na qual podemos tratar naturalmente com objetos desse tipo e, assim, formular tanto versões da teoria quântica nas quais as partículas são não indivíduos desde o início, como formular uma teoria de não indivíduos e estudá-la de um ponto de vista formal. Uma questão a mais deve ser mencionada, principalmente para o leitor interessado em fundamentos. Como explicar a quantificação em $Q$ sem fazer recurso à identidade? Em Arenhart e Krause (2009), isso é respondido nos mesmos moldes como se explica o uso dos quantificadores, por exemplo, na teoria Zermelo-Fraenkel.

Finalmente, devemos retornar à física quântica sob o ponto de vista de $Q$ e tentar desenvolver uma mecânica na qual as entidades básicas sejam assumidas como não indivíduos ab initio, podendo ser indiscerníveis e sem que se necessite introduzir truques como postulados de simetria. Iniciou-se o desenvolvimento de uma "mecânica quântica não reflexiva" (cf. French \& Krause, 2006; Domenech, Holik \& Krause, 2008; Domenech et al., 2010; Krause \& Arenhart, 2010; Krause, 2011), mas ainda há muito por ser realizado.@

Jonas Rafael Begker Arenhart Professor Doutor do Departamento de Filosofia, Universidade Federal da Fronteira Sul, Campus de Chapecó, Brasil. jonas.becker2@gmail.com

Décio Krause Professor do Programa de Pós-Graduação em Filosofia, Universidade Federal de Santa Catarina. Bolsista de Produtividade em Pesquisa do Conselho Nacional de Desenvolvimento Científico e Tecnológico, Brasil. deciokrause@gmail.com 


\begin{abstract}
It has been taken as reasonable to assume that, insofar as we deal with objects that lie beyond the formalism of physical theories, quantum physics commits us to an ontology of entities that can be assumed to be both absolutely indistinguishable and, in a sense, as lacking individuality. In this article, first, we briefly and generally consider the nature of this commitment, by discussing how it can be understood in metaphysical terms, as well as its relationship with the logical systems employed to talk about the objects to which we are committed. Then we present some of the main aspects of orthodox quantum mechanics that are usually employed to provide arguments for suggesting an ontology of objects having these features, that is, of objects that are both indistinguishable and have no individuality. Finally, we sketch the main features of quasi-set theory, a system of set theory, for the purpose of capturing formally these features in a natural way, and for employing it as the underlying logic for grounding a metaphysics of non-individuals.
\end{abstract}

KEYWORDS • Quantum mechanics. Ontology. Non-individuality. Indistinguishability. Quasi-sets.

\title{
REFERÊNGIAS BIBLIOGRÁFIGAS
}

Arenhart, J. R. B. \& Krause, D. Quantifiers and the foundations of quasi-set theory. Principia, 13, 3, p. $25^{1-68,2009 .}$

Aurang, S. How is quantum field theory possible? Princeton: Princeton University Press, 1995.

Biтвоц, M. Mécanique quantique: une introduction philosophique. Paris : Flammarion, 1996.

BLACK, M. The identity of indiscernibles. Mind, 61, 242, p. 153-64, $195^{2}$.

CAo, T. Y. (Ed.). Conceptual foundations of quantum field theory. Cambridge: Cambridge University Press, 1999.

da Costa, N. C. A. Logic and ontology. Principia, 6, 2, p. 279-98, 2002. Ensaio sobre os fundamentos da lógica. 3 ed. São Paulo: Hucitec/Edusp, 2008.

da Costa, N. C. A.; Bueno, O. A. \& Béziau, J-Y. What is semantics? Sorites, 3, p. 43-7, 1995.

Domenech, G.; Holik, F. \& Krause, D. Quasi-spaces and the foundations of quantum mechanics. Foundations of Physics, 38, p. 969-94, 2008.

Domenech, G. et al. No labeling quantum mechanics of indiscernible particles. Internacional Journal of Theorethical Physics, 49, 12, p. 3०85-91, 2010.

French, S. \& Krause, D. Identity in physics: a historical, philosophical and formal analysis. Oxford: Oxford University Press, 2006.

Jammer, M. The philosophy of quantum mechanics. New York: John Wiley \& Sons, 1974.

Krause, D. The metaphysics of non-individuality. In: Krause, D. \& Videira, A. A. (Ed.). Brazilian studies in philosophy and history of science. New York: Springer, 290, 2010. Cap. 19. (Boston Studies in the Philosophy of Science).

Krause, D. [2011], 'The problem of identity and a justification for non-reflexive quantum mechanics', pré-publicação.

Krause, D. \& Arenhart, J. R. B. Hume, Schrödinger e a individuação de objetos físicos. Revista Eletrônica de Informação e Cognição, 5, 2, p. 59-71, 2006.

Structures and models of scientific theories: a discussion on quantum non-individuality. 2010. Disponível em: <http://philsci-archive.pitt.edu/5564/1/LogUniv.pdf. >. Acesso em: 20/nov./2011.

Krause, D.; Arenhart, J. R. B. \& Moraes, F. T. Axiomatic theories and their models. 2010. Disponível em: $\langle$ http://philsci-archive.pitt.edu/5563/1/Models.pdf〉. Acesso em: 20/out./2011. 
INDISTINGUIBILIDADE, NÃO REFLEXIVIDADE, ONTOLOGIA E FÍSIGA QUÂNTICA

Krause, D. \& Videira, A.A. (Ed.). Brazilian studies in philosophy and history of science. New York: Springer, 290, 2010. (Boston Studies in the Philosophy of Science).

Kunn, T. S. Black-bodytheory and the quantum discontinuity, 1894-1912. Chicago: The University of Chicago Press, 1987 .

LÉvy-Leblond, J. M. \& Balibar, F. Quantics: rudiments of quantum physics. Amsterdam: North-Holland, 1990.

Lowe, E. J. The possibility of metaphysics: substance, identity and time. Oxford: Oxford University Press, 1998.

Penrose, R. The emperor's new mind. London: Vintage, 1989.

Pessoa Jr., O. Conceitos de física quântica. São Paulo: Livraria da Física Editora, 2003. . Conceitos de física quântica. S. Paulo: Livraria da Física Editora, 2006. V. 2.

Quine, W. V. O. From a logical point of view. New York: Harper and Row, 1964.

Rон rLich, F. On the ontology of QFT. In: CAo, T. Y. (Ed.). Conceptual foundations of quantum field theory. Cambridge: Cambridge University Press, 1999. p. 357-67.

Schrödinger, E. What is matter? Scientific American, Sept., p. $5^{2-} 7,195^{3}$.

STYER, D. S. et al. Nine formulations of quantum mechanics. American Journal of Physics, 7०, 3, p. 288-97, 2002.

Suny-Buffalo. Ontology. Buffalo: State University of New York, 2012. Disponível em: <http:// ontology.buffalo.edu/>. Acesso em: 17/jan./2012.

van Inwagen, P. Metaphysics. In: Zalta, N. E. (Ed.). The Stanford encyclopedia of philosophy. 2010 URL. Disponível em: <http://plato.stanford.edu/archives/ fall2010/entries/metaphysics/> Acesso em: 20/ out./2011.

Vickers, P. Can partial structutures accommodate inconsistent science? Principia, 13, 2, p. 195-232, 2009.

Wien Universität. Quantum optics, quantum nanophysics, quantum information laboratory. Disponível em: $\langle$ http://www.quantum.at/index.php?id=4,0 . Acesso em: 12/dez. $/ 2011$.

Zalta, N. E. (Ed.). The Stanford encyclopedia of philosophy.2010URL. Disponível em: <http:// plato.stanford.edu/archives/fall2010/entries/metaphysics/>. Acesso em: 20/out./2011. 